\section{Reflexivity in sociology}

\section{Editorial}

When I wrote my first Editorial as Editor-in-Chief of the Sociology International Journal (SIJ), published on October 10, 2018, ${ }^{1}$ I did not think that I would need to present too soon the second Editorial. However, the-fortunately positive-situation of SIJ motivates me to do this. SIJ, now completing its second year of existence, is a recent journal, but it has a number of publications that already allows us drawing some conclusions. In a concise way, we find that both the quantity and the quality of SIJ publications allow considering the growing number of published articles, in their most diverse types (such as research article, review article, mini review, short communication, and opinion, among others) that demonstrate the richness of the variety of sociological paradigmatic perspectives, as well as of addressed topics.

Sociological reflexivity is very well expressed in the wide variety of publications that can be read in SIJ. However, I want to put forward a word of support to all colleagues who, for various reasons, cannot carry out their academic activity with the intellectual freedom and the necessary-and, I would say-, the essential professional conditions to research, to know, to dispel some preconceived ideas that are naturalised and somewhat unavoidable, ${ }^{2,3}$ and, potentially, to intervene in the existing social order. ${ }^{4,5}$ From the foregoing, SIJ is fulfilling its purpose-to serve as a means of fostering the plurality of scientific publication in Sociology and in close scientific areas, without neglecting the scientific quality and rigour, which are fundamental elements that govern our action as EiC. ${ }^{1}$

So as to attain this result, and not forgetting the quality of the editorial board, the reviewers, and the manuscripts submitted by the authors for possible evaluation, I would like to highlight, for its fairness, the professionalism of the Editorial Office members in this process, and whose work is critical for the good performance of SIJ.

For the reasons set forth above, I believe that there are the vital conditions for SIJ to seek to increase its visibility by continuing its gradual indexation to databases of acknowledged scientific merit.

I shall conclude by wishing the most fruitful sociological reflections for all, and that SIJ continues to be worthy of your trust.
Volume 2 Issue 6 - 2018

\author{
Sandro Serpa \\ Department of sociology, University of the Azores, Portugal
}

Correspondence: Sandro Serpa, University of the Azores, Faculty of Social and Human Sciences, Department of Sociology, Interdisciplinary Centre of Social Sciences - CICS.UAcl CICS.NOVA.UAc, Interdisciplinary Centre for Childhood and Adolescence-NICA-UAc, Ponta Delgada, Portugal,Tel 351964424554,Email sandvo.nf.serpa@uac.pt

Received: December 09, 2018 | Published: December 12,
2018

\section{Funding}

University of the Azores, Interdisciplinary Centre of Social Sciences-CICS.UAc/CICS.NOVA.UAc, UID/SOC/04647/2013, with the financial support of the FCT/MEC through national funds and when applicable co-financing from the FEDER under the PT2020 Partnership Agreement."

\section{Conflict of interest}

The author declares that there is no conflict of interest.

\section{References}

1. Serpa S. Quality and democraticity in scientific dissemination. Sociology International Journal. 2018;2(5):429-430.

2. Pisonero CG, Manso AG. Childhood and biopolitics in the 21 st century: A scenario yet to be described. Sociol Int J. 2018;2(6):556-558.

3. Rozenberg JJ. Corps raciology and cultural relativism. Sociol Int J. 2018;2(5):394-396.

4. Ferreira CM, Serpa S. Contemporary challenges for the academic. International Journal of Contemporary Education. 2018;2(1):1-8.

5. Rittberger B, Richardson J. What happens when we do not defend academic freedom? Journal of European Public Policy. 2017;24(1):1-10. 